\title{
The Role of Managed Care Pharmacy in Reducing Medication Errors
}

\author{
MATTHEW C. GRISSINGER, RPh; NANCY J. GLOBUS, PharmD; and MATTHEW P. FRICKER, JR., MS, RPh
}

\begin{abstract}
OBJECTIVE: To outline some of the causes of medication errors and recommend ways that managed care pharmacy organizations and managed care pharmacists can prevent some of these errors through practitioner and patient education.

BACKGROUND: Patient safety has become a major concern since the November 1999 release of the Institute of Medicine (IOM) report, To Err Is Human. Errors involving prescription medications are responsible for up to 7,000 American deaths per year and the financial costs of drug-related morbidity and mortality may cost nearly $\$ 77$ billion a year. The Institute for Safe Medication Practices (ISMP) collects and analyzes voluntary confidential medication error reports and makes recommendations on the prevention of these errors. This article uses the expertise of ISMP in medication error prevention to make recommendations on educational programs for patients and managed care and community pharmacists to reduce medication errors in the outpatient (community) setting. These educational areas focus on patient education, compliance, and health care literacy.
\end{abstract}

CONCLUSION: Managed care pharmacy is well positioned to affect change in the health care system. Through information dissemination and education, managed care pharmacists should play a more active role in medication error-reduction activities by improving the patient education process and in assisting the pharmacy community in its goal of improving patient safety.

KEYWORDS: Medication error, Patient education, Patient compliance, Health care literacy, Patient safety

J Managed Care Pharm. 2003(9)1: 62-65

\section{Author}

MATTHEW C. GRISSINGER, RPh, is Medication Safety Analyst at the Institute for Safe Medication Practices (ISMP), Huntingdon Valley, Pennsylvania; NANCY J. GLOBUS, PharmD, is Medication Safety Analyst at Med-E.R.R.S., a subsidiary of ISMP; and MATTHEW P. FRICKER, Jr., MS, RPh, is Manager for Special Services at ISMP.

AUTHOR CORRESPONDENCE: Matthew C. Grissinger, RPh, Medication Safety Analyst, Institute for Safe Medication Practices, 1800 Byberry Road, Suite 810, Huntingdon Valley, PA. 19006-3520. Tel: (215) 947-7797; Fax: (215) 914-1492 E-mail: mgrissinger@ismp.org

Copyright $\odot$ 2003, Academy of Managed Care Pharmacy. All rights reserved.
$\mathrm{P}$ atient safety has become a major concern since the November 1999 release of the Institute of Medicine (IOM) report, To Err Is Human. Health care practitioners may have been surprised to learn from this report that errors involving prescription medications are responsible for up to 7,000 American deaths per year and that the financial costs of drug-related morbidity and mortality may cost nearly $\$ 77$ billion a year. ${ }^{1}$ A retrospective analysis of medication errors reported to the U.S. Food and Drug Administration Adverse Event Reporting System from 1993 to 1998 showed that fatal medication errors accounted for approximately $10 \%$ of medication errors reported. ${ }^{2}$

Research demonstrates that injuries resulting from medication errors are not the fault of any individual health care professional but, rather, represent the failure of a complex health care system. Medication error prevention starts with recognizing that errors are multifactorial and are faults of the system as a whole rather than results of the acts or omissions of the people in the system. ${ }^{3}$ Even when an error can be directly traced to a specific individual (e.g., the pharmacist dispensing and the nurse administering the wrong medication to the patient), further investigation will determine that a variety of factors such as poor order communication between the physician and pharmacist, dangerous storage practices in pharmacies, and look-alike labeling may have played a role in the error.

The key elements that make up the medication-use system include patient information; drug information; communication of drug information; drug packaging, labeling, and nomenclature; drug device acquisition and use; drug storage, stock, and distribution; environmental factors; staff competency and education; patient education; quality processes; and risk management. ${ }^{4}$ Patient education is one of the areas in which a managed care pharmacist can have the greatest impact in reducing medication errors.

The patient usually is the last individual in the medication-use process, and the pharmacist-patient interface can play a significant role in capturing medication errors before they occur. Unfortunately, many health care organizations do not take advantage of this key interaction opportunity. There are 3 important factors that play a role in any patient interface, which often determines the outcome of error prevention efforts. These include patient education, patient and health care literacy, and patient compliance.

\section{Patient Education}

In 2001, the number of retail prescriptions was 3.3 billion, which is an increase from 2.7 billion in 2000. By 2004, this figure is estimated to exceed 4 billion. ${ }^{5}$ This increase in prescrip- 
tion volume, when combined with the shortage of pharmacists, often results in a decrease in the amount of time available for direct pharmacist involvement in patient education. Studies have shown that pharmacy staff is not routinely involved in direct patient education. A 1999 study involving community pharmacies in 8 states revealed that $87 \%$ of all patients received written information with their prescriptions. However, only $35 \%$ of pharmacists made any reference to the written leaflet, and only $8 \%$ actually reviewed it with the patient. ${ }^{6}$ Sometimes health care practitioners take for granted that patients fully understand the instructions given during the patient education process. Unfortunately, patients often misunderstand the instructions. The Institute for Safe Medication Practices (ISMP) received a report about an asthmatic patient who was not responding to therapy. During follow-up, the patient described how he was using his inhaler. He would get into his car, roll up the windows, release 2 puffs of medication into the air, and breathe deeply for 15 minutes! At first, he did this in his house. Later he thought it might be more effective to use the inhaler in a confined space. He said he'd been instructed to do this by his doctor, who had picked up an inhaler, held it in the air, and released 2 puffs to demonstrate its use. The doctor gave no additional instructions. Additional examples of errors that have occurred due to inadequate education on medications include parents placing oral antibiotic suspensions into a child's ear for an ear infection, patient's taking the desiccant that comes packaged with oral medications, wrong medications being dispensed that are undetected by a patient due to the lack of counseling while in the pharmacy, and errors related to patient use of devices because of inadequate education (data from the U.S. Pharmacopeia (USP/ISMP) Medical Error Reporting Program). This gap in patient education is exacerbated by the failure of health care practitioners to provide patients with understandable written instructions.

\section{Patient and Health Care Literacy}

The second factor in error prevention is patient literacy, which includes general literacy levels and health care literacy. Many people have difficulty understanding their illness or disease, the proper management of it, and their role in maintaining their health. Whether limited by knowledge, socioeconomic factors, emotional or clinical state, or cultural background, their level of health literacy - the ability to read, understand, and act on health care information-is often much lower than many health care providers may appreciate.

Examples of patients who have had difficulty reading and understanding medication directions are plentiful: an elderly patient who could not tell the difference between his bottle of Coumadin (warfarin) or Celebrex (celecoxib); a mother who, after reading the label on a bottle of acetaminophen, could not accurately state her child's dose; and a teenager who misunderstood directions for contraceptive jelly and ate it on toast every morning to prevent pregnancy. These occurrences are adapted from medication error reports submitted to the USP/ISMP Medication Error Reporting Program. The ISMP provides an independent review of confidentially reported medication errors that have been voluntarily submitted by practitioners to a national Medication Errors Reporting Program operated by the USP. Poor health literacy is not an isolated problem with the elderly, uneducated, or certain socioeconomic classes. ${ }^{7}$

According to a report published by the American Medical Association Ad Hoc Committee on Health Literacy, more than $40 \%$ of patients with chronic illnesses are functionally illiterate, and almost a quarter of all adult Americans read at or below a 5 th-grade level. Unfortunately, medical information leaflets typically are written at a 10th-grade reading level or above. It is estimated that low health-literacy skills have increased our annual health care expenditures by $\$ 73$ billion. Further contributing to the dilemma is the fact that an estimated three quarters of patients throw out the medication leaflet stapled to the prescription bag without reading it, and only one half of all patients take their medications as directed. ${ }^{8}$

One reason for this lack of understanding may be that people who have difficulty reading or understanding health information are too embarrassed or ashamed to acknowledge their deficits. Instead, they refuse to ask questions and often pretend to understand instructions. In addition, low literacy is not obvious. Researchers have reported poor reading skills in some of the most poised and articulate patients. ${ }^{5}$

\section{Patient Compliance}

Compliance is the third patient-related factor contributing to medication errors. One study found a 76\% difference between medications patients actually are taking as compared to those recorded in their charts as being prescribed. Confusion that may accompany advancing age combined with an increase in the number of medicines prescribed for patients are the 2 factors most likely to contribute to this high rate of discrepancy. ${ }^{9}$ Another study demonstrated that patient noncompliance played a role in $33 \%$ of hospital admissions. ${ }^{10}$ Noncompliance may be exhibited by patients in many ways, such as not having a prescription initially filled or refilled, dose omission, taking the wrong dose, stopping a medication without the physician's advice, taking a medication incorrectly or at the wrong time, taking someone else's medication, and the financial inability to purchase their medications. Patients at risk for being noncompliant include patients taking more than one drug, patients with a chronic condition who are on complex drug regimens that may result in bothersome side effects, patients who take a drug more than once daily, and patients who have a condition that produces no overt symptoms or physical impairment, such as hypertension or diabetes. ${ }^{11}$ In addition, the elderly patient is more at risk for drug-related problems such as noncompliance due to factors such as decrease in mental acuity and increased confusion, lack of family or caregiver support, decreased coordination and dexterity, and impaired vision. ${ }^{12}$ The managed care 
pharmacist must consider these factors in the development of patient education tools, strategies, and methods.

\section{Recommendations}

Managed care pharmacy organizations can play a significant role in preventing medication errors through patient education. Success may require employing new techniques for providing patients with the information they need and ensuring that it is understood. First, pharmacists should assume that every person has low-level health care literacy even if they do not have a general literacy problem. Secondly, regardless of their level of understanding, most people prefer simple, straightforward instructions and written materials. Managed care pharmacy needs to address patient education issues at the organizational level and promote these activities among the provider pharmacies. Important organizational factors to keep in mind are recommendations that have been compiled from many years of medication error reporting and analysis at ISMP as well as longstanding relationships with many patient safety organizations. These recommendations include the following:

- Develop and implement programs to increase patient compliance (e.g., educational interventions, monitoring activities, and compliance packaging aids). Keep health care providers informed about these programs so they can refer appropriate patients as part of an individualized compliance regimen.

- Develop and implement innovative programs that promote the patients' responsibility for and involvement in their health care.

- Review drug-use policies, such as formulary policy guidelines, from a patient compliance perspective. Revise policies accordingly to facilitate compliance.

- Individualize patient care, including medication management, considering factors such as age, culture, gender, attitudes, and personal situation.

- Use existing databases (e.g., pharmacy claims data) to profile the extent of medicine noncompliance among your health plan members. Devise a mechanism to bring these patients to the attention of all relevant health care providers.

- Provide written materials at a 5th-grade reading level or lower. Use clear captions, ample white space, and pictures, diagrams, or videotapes to help explain concepts. Most people, even those who read well, depend on visual clues to reinforce learning and spark memory.

- Involve patients when producing patient education material. Use focus groups of patients to help write personally relevant and culturally sensitive education materials. After they understand the information, ask patients how you should explain it to others. Use a different focus group of patients to review the final materials and highlight any word or concept they do not fully understand.

Managed care organizations should encourage patients to become engaged participants in treatment decisions and solving problems that could inhibit proper medication use. Patient education materials should be developed to engage patients in their own care to

- ask their health professionals about the purpose of and proper use of their medications and to make sure they understand the response they receive;

- read the label every time they take their medication;

- know what their medication should look like;

- keep medications in original containers;

- never take someone else's medication;

- check their medications every 6 months for their expiration date and don't save old medications;

- ask their doctor or pharmacist if the medication comes in a liquid if swallowing medications is problematic;

- ask for assistance when purchasing over-the-counter medications; and

- keep a current list of their medications. (This medication profile should include the name, strength, dose, and frequency of dosage of all prescription medications; name of all over-the-counter medicines, vitamins and herbal products, and dietary supplements; known medication and food allergies; and medications that the patient used to take and the reason why the medication was discontinued.)

Managed care organizations must reach out and partner with the community/ambulatory pharmacies in preventing medication errors through patient education efforts. An example of this collaboration may be for the managed care organization to provide continuing education programs to community pharmacists since they may not be fully aware of ways to reduce adverse events or to provide preferred methods of managing errors when they occur. Training programs should incorporate patient communication skills and new teaching methods as well as encourage pharmacies to become proactive about gathering and providing medication information. Pharmacists should concentrate on learning to

- provide written materials to the patient to reinforce oral counseling, not as a substitute for it;

- engage in a dialogue with patients and involve them as partners in the medication use process;

- offer small amounts of information at a time, first telling patients what they truly need to know to follow directions, emphasizing desired behavior, not the medical facts, and leaving background information for later encounters;

- verify that the patient understands the drug information provided (avoid asking yes/no questions; instead ask patients to show and tell you how they would take their medicine so that you can spot problems); and

- provide compliance monitoring and documentation for at least one at-risk patient per month. Share your findings with the patient and with his or her other health care providers, including the managed care pharmacy.

\section{Conclusion}

Managed care pharmacy is well positioned to affect change in 
The Role of Managed Care Pharmacy in Reducing Medication Errors

the health care system. Through information dissemination and education, managed care pharmacists should play a more active role in medication error-reduction activities by improving the patient education process and in assisting the pharmacy community in its goal of improving patient safety.

\section{DISCLOSURES}

No outside funding supported this study. Matthew C. Grissinger served as principal author of the study. Study concept and design and anaylsis and interpretation of data were contributed by Grissinger and authors Matthew P. Fricker, Jr., and Nancy J. Globus. Drafting of the manuscript was primarily the work of Grissinger and critical revision of the manuscript was the work of Fricker and Globus.

\section{REFERENCES}

1. Kohn LT, Corrigan JM, Donaldson MS, eds. To Err Is Human: Building a Safer Health Care System. Institute of Medicine Report, November 29, 1999. Available at: http://bob.nap.edu/html/to_err_is_human/. Accessed September 14,2002

2. Phillips J, Beam S, Brinker A, et al. Retrospective analysis of mortalities associated with medication errors. Am J Health-Syst Pharm. 2001;58:1835-41.

3. Leape LL, Bates DW, Cullen DJ, et al. Systems analysis of adverse drug events. JAMA. 1995;274:35-43.
4. Cohen MR, Smetzer JL. In: Cohen MR, ed. Medication Errors. Washington, DC: APhA; 1999:20.4-20.12

5. www.ismp.org/msaarticles/whitepaper.html. Accessed August 7, 2002.

6. Svarstad, B. University of Wisconsin-Madison, FDA-commissioned research presented in February 2000, Rockville, MD, and in June 2000, Kuopio, Finland.

7. ISMP Medication Safety Alert! Volume 6, issue 22, October 31, 2001

8. AMA: Ad Hoc Committee on Health Literacy for the Council on Scientific Affairs. Health literacy: report of the Council on Scientific Affairs. JAMA 1999;281:552-57.

9. Bedell SE, Jabbour S, Goldberg R, et al. Discrepancies in the use of medications: their extent and predictors in an outpatient practice. Arch Intern Med. $2000 ; 160: 2129-34$

10. McDonnell PJ; Jacobs MR. Ann Pharmacother. 2002;36(9):1331-36.

11. http://www.talkaboutrx.org/compliance.html. Accessed October 30, 2002. 12. Lombardi TP, Kennicutt JD. Promotion of a safe medication environment: focus on the elderly and residents of long-term care facilities. www.medscape.com/. Accessed May 14, 2001. 